\section{On the Relationship of Male Sexual Dysfunction and Ankylosing Spondylitis}

\section{To the Editor:}

We have read the recent paper by Dr. Fan and colleagues on the relationship of male sexual dysfunction and ankylosing spondylitis (AS) ${ }^{1}$.

We are interested in the study because of our publication, "Impact of ankylosing spondylitis on sexual function: a systematic review and metaanalysis" 2 . While we have great esteem for all the efforts the authors have taken to explore the association of male sexual dysfunction with AS, we fear that fundamental flaws in inclusion and exclusion criteria preclude convincing conclusions.

In the Abstract section, "score of the International Index of Erectile Function (IIEF) was used as the outcome measurement" was inconsistent with the Results section, where it was stated, "Among these studies, 6 used the IIEF, 1 used the Brief Male Sexual Function Inventory, 1 used the Glombok-Rust Sexual Satisfaction Scale, 1 used the self-estimated intravaginal ejaculatory latency times, and 2 used self-administrated questionnaires to measure patients' sexual function." If different standards are applied, the results will be controversial owing to different standards possessing different items and score ranges. Dincer, et al used Brief Male Sexual Function Inventory, and score ranges were erectile function (EF; $0-12)$, sexual drive (SD; $0-8)$, and overall satisfaction $(\mathrm{OS} ; 0-4)^{3}$. The other 5 studies applied IIEF (EF 1-30, SD 2-10, and OS 2-10), results distinctly different from the Brief Male Sexual Function Inventory. We do not think that the IIEF and Brief Male Sexual Function Inventory should be combined. The metaanalysis was performed in only 5 or 6 studies, while 11 studies were included in the research. What about the other included studies?

The Fan article states, "The graphical funnel plots of the 6 studies appeared to be symmetrical." However, that description was conflicting with another statement: "It is possible that publication bias has been introduced as indicated by the funnel plot, which seemed to be asymmetric." We are confused about whether publication bias exists or not.

The majority of the data of $\mathrm{Xu}$, et $a l^{4}$ and Pirildar, et $a l^{5}$ were the same, except for the number of participants. However, the authors did not exclude the repeated studies. Therefore, the result is uncertain unless the metaanalysis was re-performed.

Metaanalysis is a useful approach to assess and synthesize the results of pertinent studies to draw conclusions, which could enhance the statistical power and provide evidence for clinicians. Accordingly, the quality of included studies is very important. A more strictly designed metaanalysis will be necessary before reliable conclusions can be reached.

YA-FEI LIU, MD, Institute of Integrated Traditional Chinese and Western Medicine, Tongji Hospital, Tongji Medical College, Huazhong University of Science and Technology, Wuhan, Hubei, and Department of Nephrology, The First Affiliated Hospital of Zhengzhou University, Zhengzhou, Henan, China; CAI-YU-ZHU WEN, MD, Hubei University of Chinese Medicine, Wuhan, Hubei; SHENG-HAO TU, MD, Institute of Integrated Traditional Chinese and Western Medicine, Tongji Hospital, Tongji Medical College, Huazhong University of Science and Technology, 1095 Jiefang Ave., Wuhan, Hubei 430030, China. Address correspondence to Dr. S.H. Tu; E-mail: shtu@tjh.tjmu.edu.cn.

\section{REFERENCES}

1. Fan DZ, Liu L, Ding N, Liu S, Hu YT, Cai GQ, et al. Male sexua dysfunction and ankylosing spondylitis: a systematic review and metaanalysis. J Rheumatol 2015;42:252-7.

2. Liu YF, Dong H, Chen Z, Wang Y, Tu SH. Impact of ankylosing spondylitis on sexual function: a systematic review and meta-analysis. Exp Ther Med 2015;9:1501-7.

3. Dincer U, Cakar E, Kiralp MZ, Dursun H. Assessment of sexual dysfunction in male patients with ankylosing spondylitis. Rheumatol Int 2007;27:561-6.

4. Xu Q, Yang J, Zhang L. [Sexual dysfunction in men with ankylosing spondylitis.] [Article in Chinese] Mod Med J Chi 2007;9:63-5.

5. Pirildar T, Müezzinoğlu T, Pirildar S. Sexual function in ankylosing spondylitis: a study of 65 men. J Urol 2004;171:1598-600.

J Rheumatol 2015;42:12; doi:10.3899/jrheum.150517 